\title{
Current changes in English syntax
}

Christian Mair and Geoffrey Leech

\section{Introduction}

Syntactic change differs from lexical change in at least two important ways. First, it generally unfolds much more slowly, sometimes taking hundreds of years to run its course to completion, and secondly, it tends to proceed below the threshold of speakers' conscious awareness, which makes impressionistic or introspection-based statements on ongoing changes in English grammar notoriously unreliable. A third difficulty in pinning down syntactic change in present-day English is that a rather small number of alleged syntactic innovations are strongly stigmatised. This has biased discussion in favour of such high-profile issues at the expense of developments which are, arguably, more comprehensive and farreaching in the long run. Examples which come to mind include the use of like as a conjunction (as in And it looks like we could even lose John) or the use of hopefully as a sentence adverb (Hopefully, they'll go back and set it up). ${ }^{1}$ Such shibboleths have aroused an inordinate amount of expert and lay comment, while developments which appear to be systematically if gradually transforming the grammatical core of standard English, such as the continuing increase in the frequency of the progressive aspect or the spread of gerundial complements at the expense of infinitival ones (see section 4 below), tend to go largely unnoticed.

We define "current" changes in English as those developments for which there has been a major diachronic dynamic since the beginning of the 20th century. For practical reasons, we focus largely on the written standard forms of English in Britain and the United States, fully aware that this strategy will prevent us from including some cutting-edge innovations in

\footnotetext{
${ }^{1}$ It is only the second case which represents a genuine innovation - with a first OED attestation from 1932 (s.v. hopefully, adv. 2); the use of like as a conjunction can be documented from the Early Modern English period
} 
contemporary spoken English which are likely to be incorporated into the standard in the long run.

When it comes to analysing syntactic change, there are two approaches. Where the focus is on the diachronic development of grammars as decontextualised linguistic systems, syntactic change is often seen as an abrupt or discrete alteration of structures, rules and constraints (e.g. in the generativist tradition embodied in the work of David Lightfoot - from Lightfoot, 1979 to Lightfoot, 1999). But where the starting point for the analysis of historical change is the study of recorded performance data in their linguistic and social context - as, for example, in grammaticalisation theory (Hopper/ Traugott, 2003) or the budding field of historical sociolinguistics (cf. Nevalainen/ Raumolin-Brunberg, 2003) - the picture that emerges is one of gradual evolution rather than abrupt change. Syntactic changes are seen as embedded in a context where semantic, pragmatic and sociolinguistic factors assume roles as determinants of change. However, even those scholars who conceive of syntactic change in terms of discrete steps will agree that the spread of linguistic innovations throughout the community (or conversely, the dying out of obsolescent forms) is a gradual phenomenon. It is understandable, then, that in the time-span of the one century that is the focus of this chapter, we are unlikely to see any one change run out its full course, from inception in particular genres, registers or discourse communities, to full establishment in the core standard grammar. What we are able to note, though, are shifting frequencies of use for competing variants which - over the course of a century - may well build up into impressive statistical trends.

Not only will a change proceed gradually (if one looks at the language as a whole), but it will also proceed at differential speeds in different regional varieties of English and different styles and textual genres. This is why, after a necessarily brief review of the literature on ongoing grammatical change in present-day English, the present chapter will largely be corpus-based, 
focusing on the examination of substantial samples of different varieties of writing at different times. As a point of departure we will take mid-twentieth-century standard American and British written English as documented in two widely known and widely used matching reference corpora, namely the Brown and LOB corpora. To cover developments towards the end of the twentieth century, we will also use the Frown and F-LOB corpora, which were built to match Brown and LOB as closely as possible in size and composition but contain texts published not in 1961, as the originals do, but in 1992 and 1991 respectively. $^{2}$ The four equivalent corpora are available in untagged and tagged versions, ${ }^{3}$ making it feasible to study changes in textual frequency in terms of not only individual words and word sequences but also of grammatical categories. ${ }^{4}$ Beyond the limitations of the written medium and the thirtyyear period spanned by these corpora, we will where necessary extend our evidential base by making use of other electronic text resources, such as small collections of spoken data ${ }^{5}$ and the corpus formed from OED quotations.

\section{Some important previous studies}

The popular literature on ongoing changes in the English language (see Barber, 1964 or Potter, 1975 for two typical examples) tends to focus on phonetic and lexical rather than

eyes of many writers.

${ }^{2}$ The four corpora each contain about a million words of running text, sampled in 500 chunks of c. 2,000 words each and covering a range of fifteen written genres. They are available from ICAME, the International Computer Archive of Modern and Medieval English, in Bergen, Norway, whose homepage contains further relevant information. See http://www.hit.uib.no/corpora.html.

${ }^{3}$ By a tagged corpus, we mean a corpus in which each word token is supplied with a grammatical label specifying its part of speech - see Mair et al. (2002) for further details.

${ }^{4}$ Much of the corpus-based research reported here, particularly that based on the LOB, F-LOB, Brown and Frown corpora, has been carried out collaboratively by the authors, their colleagues and researchers at the Universities of Freiburg and Lancaster. Regarding the Lancaster work, thanks are due to Nicholas Smith, who undertook most of the automatic corpus processing and a considerable amount of the manual analysis. We also gratefully acknowledge the support of the Arts and Humanities Research Board and the British Academy (Leech) and Deutsche Forschungsgemeinschaft (Mair), who provided research funding.

\footnotetext{
${ }^{5}$ See note 10 for further details of the spoken corpora used. Corpus-based real-time studies of changes in the
} grammar of the spoken language will be encouraged by the creation of "a parsed and searchable diachronic 
grammatical change. Among grammatical changes the emphasis is on cases which have aroused the concern of prescriptivists. A typical list of changes suspected to be going on in present-day standard English is the following one, which is largely based on Barber (1964, p. 130-144):

a. $\quad$ a tendency to regularise irregular morphology (e.g. dreamt $\rightarrow$ dreamed)

b. revival of the "mandative" subjunctive, probably inspired by formal US usage (we demand that she take part in the meeting)

c. elimination of shall as a future marker in the first person

d. development of new, auxiliary-like uses of certain lexical verbs (e.g. get, want - cf., e.g., The way you look, you wanna / want to see a doctor soon) ${ }^{6}$

e. extension of the progressive to new constructions, e.g. modal, present perfect and past perfect passive progressive (the road would not be being built/ has not been being built/ had not been being built before the general elections)

f. increase in the number and types of multi-word verbs (phrasal verbs, have/take/give a ride, etc.)

g. placement of frequency adverbs before auxiliary verbs (even if no emphasis is intended - I never have said so)

h. do-support for have (have you any money? and no, I haven't any money $\rightarrow$ do you have/ have you got any money? and no, I don't have any money/ haven't got any money)

i. demise of the inflected form whom

j. $\quad$ increasing use of less instead of fewer with countable nouns (e.g. less people)

k. $\quad$ spread of the s-genitive to non-human nouns (the book's cover)

corpus of present-day spoken English", which is under way at the Survey of English Usage (University College London); see http://www.ucl.ac.uk/english-usage/diachronic.index.htm for details.

${ }^{6}$ While it is not referred to as such in the literature aimed at wider audiences, this is an obvious case of grammaticalisation: the gradual incorporation of lexical material into the grammar of the language. 
1. omission of the definite article in certain environments (e.g. renowned Nobel laureate Derek Walcott)

m. "singular" they (everybody came in their car)

n. like, same as, and immediately used as conjunctions

o. a tendency towards analytical comparatives and superlatives (politer $\rightarrow$ more polite)

Of these, a-h belong to the sphere of the verb phrase, while i-m belong to the sphere of the noun phrase (n-o belong to neither). Certain of these supposed changes do have support from corpus evidence - b, c, d, e, h, i, l, m - although in some cases the focus of change as listed above is misleading. Thus shall (item c) has been undergoing a general decline, not restricted to the first person. Similarly, the s-genitive (item k) has been showing a general increase, not specific to non-human nouns.

Note that defining many of these changes as "current" or "ongoing" means stretching the concepts somewhat. Whom, for example, has been optionally replaceable by who in many common uses since the Early Modern English period. By the $19^{\text {th }}$ century, it was a marker of formal style, really obligatory only if preceded by a preposition. This is very much the situation today, and so any report that whom is on its deathbed is, to say the least, premature (see 3 below). Similarly, most of the truly recent change in the comparison of disyllabic adjectives (item o) has not been in the direction of more analyticity but of reducing the variability of forms for individual adjectives (Bauer 1994, p. 80).

Some recent work on ongoing change has combined the corpus-based approach with other methods in detailed studies of lexicogrammatical phenomena. Rickford et al. (1995), for example, traced the recent emergence of the topic-introducing preposition as far as (e.g. "as far as my situation, I am less than optimistic ..."), which they see as having been derived from clauses of the type as far as $X$ is concerned through a process of grammaticalisation. Some time before that, and without mentioning the technical term "grammaticalisation" - the heading under which such processes would almost certainly be subsumed in current work on 
syntactic change - Olofsson (1990) traced a similar development, namely the emergence of prepositional uses of following, splitting off from the mainstream use of the form as a participle in nonfinite clauses. The emergence of (be) like as a quotation-introducing form in some spoken registers of American English (and increasingly in British English) is the focus of a study by Romaine and Lange (1991). Such studies, while valuable in themselves, say little about the language as a whole. It is difficult to generalise from their results, and an investigation of such cases will probably not direct the linguist to those parts of the grammatical core which are undergoing potentially far-reaching change.

Among recent work on current grammatical change, two publications deserve special mention because they aim to meet higher methodological standards than the rest: Bauer (1994) stands out in seeking to support all statements he makes with textual evidence, and Denison (1998) offers a magisterial survey of developments in English grammar since 1776 that is unrivalled in its comprehensiveness. Denison, who as a contributor to volume IV of the Cambridge History of the English Language covers the period from 1776 to 1997 , focuses on the $19^{\text {th }}$ and early $20^{\text {th }}$ centuries and on continuities with the preceding Early Modern English period treated in volume III of the same work, rather than on recent and current change.

Nevertheless, for our purpose, Denison's work goes beyond that of others in providing a list of suspected changes in $20^{\text {th }}$-century English which is based on a systematic sifting of the available evidence rather than on anecdotal observations and narrow prescriptive concerns.

\section{The role of corpora in investigating current changes}

One important role of corpora in the study of ongoing grammatical change is "negative": they can provide evidence that some suspected change has not actually been proceeding in the assumed direction in a given period of time. For an example we return to the "demise" of whom - widely assumed to be inevitable ever since Sapir put the case for it in his classic Language (1921, p. 166-174), but clearly not substantiated by later corpus findings. In the 
four corpora (LOB, Brown, F-LOB and Frown) providing the evidential database for the present chapter the following figures are obtained:

Table 1: Whom in four matching corpora

\begin{tabular}{|l|l|l|l|}
\hline & 1961 & $1991 / 2$ & Difference (\%age of 1961) \\
\hline British English (LOB/ F-LOB) & 217 & 177 & $-18.4 \%$ \\
\hline American English (Brown/ Frown) & 144 & 166 & $+15.3 \%$ \\
\hline
\end{tabular}

If anything, such figures show that there is fluctuation, or even convergence between the two major regional standards, rather than an overall decrease. ${ }^{7}$ Synchronic results for the late 20th century based on the one-hundred-million-word British National Corpus (BNC) are also instructive. With a total raw frequency of 12,596 , or c. 129 occurrences per million words, whom cannot exactly be called a rare word. Its function as a style marker, however, becomes obvious once one looks at the frequencies in different textual genres. 141 instances per million for written English (with outliers beyond 200 in the more formal genres) contrasts with 26 per million overall for spoken English, and as little as 5 per million in the spontaneous dialogue of conversation.

The most valuable role of corpora in the study of syntactic change, however, is not the "negative" one of refuting wrong hypotheses, but their "positive" role, which manifests itself either in a differentiated confirmation of an existing assumption or - even more valuable - in the discovery of ongoing changes which have not even been noticed by observers so far. The following sections 4 to 6 will give such "positive" corpus evidence for the recent development of grammatical constructions, for many of which Denison's 1998 survey has noted a pronounced diachronic dynamic since the late $18^{\text {th }}$ century. It is likely, therefore, that

\footnotetext{
${ }^{7}$ This goes against previous research based on other corpora, in which results did point towards a decline in the discourse frequency of whom in spoken and written English in the late 20th century (Aarts and Aarts 2002, p. 128).
} 
these changes are still with us today, and can be considered truly current. With some of them, such as the get-passive or the going-to future, the crucial structural changes had already taken place before the year 1776, Denison's starting point, so that any statistical increase in material from c. 1900 is likely to represent a spread of these innovations - for example, from less formal into more formal registers and styles (see, e.g., Hundt, 2001 or Mair, 1997). However, some other structures (for example certain new progressives, on which see 4.1. below) represent genuine recent innovations in the sense that they were not firmly established in any style before the $20^{\text {th }}$ century.

Although the spotlight tends to fall on innovatory changes and their diffusion, corpora also provide evidence of changes in the direction of attenuation and loss. For example, the four corpora show a declining frequency in the use of many modal auxiliaries and of wh-relative pronouns. We will examine these, together with gains in apparently competing categories so-called semi-modals like going to, and that- and zero relativisation - in sections 4 and 5 .

\section{The changing verb phrase}

\subsection{Progressive aspect}

Although our four one-million-word corpora are too small to yield definitive findings for rare grammatical constructions, they are more than sufficient in size to investigate major current trends in the tense, modality, aspect and voice systems of English, in particular the continuing spread of the progressive form. Here two different phenomena need to be distinguished:

- $\quad$ an increase in the frequency of occurrence of progressives in general, and

- $\quad$ the establishment of the progressive in a few remaining niches of the verbal paradigm in which it was not current until the 20th century.

Both phenomena represent direct $20^{\text {th }}$ century continuations of well-established long-term trends. The fairly dramatic increase in the frequency of the progressive from late Middle English onwards has been confirmed, for example, by Jespersen (1909-49: IV, 177), who used 
Bible translations from various periods as parallel historical corpora. ${ }^{8}$ Today's filling of structural gaps in the verbal paradigm also builds on such previous episodes, for example the emergence of the progressive passive (dinner was being prepared) approximately 200 years ago, superseding "passival" dinner was preparing (on which see Denison 1998, p. 148ff.). Mair/ Hundt (1995) have obtained the following figures in a manual analysis of all progressive forms in the press sections (A-C, ca. 176,000 words each) of the four corpora:

Table 2: Progressive forms in the press sections (A-C) of the four reference corpora

\begin{tabular}{|l|l|l|l|}
\hline & 1961 & 1991/92 & Difference (\%age of \\
& & & 1961) \\
\hline British English (LOB/ F-LOB) & 606 & 716 & $+18.2 \%$ \\
\hline American English (Brown/ Frown) & 593 & 663 & $+11.8 \%$ \\
\hline
\end{tabular}

(significances: LOB-F-LOB $\mathrm{p}<0.01$, Brown-Frown $\mathrm{p}<0.05$; LOB-Brown and F-LOB-Frown $\mathrm{p}>0.05$ )

As can be seen, the increases observed are statistically significant both in the British and the American data, which is not the case for the regional contrasts to be observed between British and American English at any one time. Further research on the tagged versions of the entire two British corpora was carried out by Nicholas Smith (2002), who noted a highly significant increase of $28.9 \%$ - from 980 to 1263 - for the present active progressive. Smith's equivalent provisional figures for Brown and Frown show a very similar trend (an increase of $31.8 \%$ from 996 to 1316). ${ }^{9}$ However, the growth in progressive usage is patchy: the comparison

\footnotetext{
${ }^{8}$ Jespersen's way of making his point is obvious and elegant. More fine-grained and differentiated statistical evidence is provided by Nehls (1988), among others.

${ }^{9}$ Although the Brown and Frown corpora have been part-of-speech tagged, this has been done automatically, so far without manual post-editing, so that a tagging error rate of c. $2 \%$ currently remains in the corpora. This means that these figures for Brown and Frown, in particular, are likely to need some minor correction when the necessary editing work has been done. The broad trends shown in this and other tables in this chapter are, however, very unlikely to be affected by such changes. It is in the nature of corpus linguistic research that some revision of the quantitative data will arise from further scrutiny and analysis of the same data. All our figures are in this sense provisional.
} 
between LOB and F-LOB shows a particularly high increase in the modal progressive - e.g. should be leaving - (29.3\%) and in the passive progressive - e.g. is being held - (31.3\%), while the past progressive actually shows a decrease of $9.0 \%$. Moreover, the steep increases in the modal and passive progressive in the British corpora are not matched by similar increases in the American corpora.

However, that there has been a general and significant increase in the frequency of progressives in the course of the $20^{\text {th }}$ century seems beyond doubt. What is more difficult to provide is a convincing explanation. Are we dealing with an instance of grammatical change directly, or are we seeing one grammatical symptom of a more general stylistic change, in which the norms of written English have moved closer to spoken usage, where the progressive has presumably always been more common than in writing? (See, for example, the findings in Biber et al. 1999, p. 461-63.) There is little sign of the progressive extending its territory by combination with 'non-progressive' verbs like the stative know and wish. Even where in particular cases such uses can be shown to be recent, they are far too rare to play a role in accounting for the statistical increase which is documented in the corpora. ${ }^{10}$ On the other hand, one use of the progressive seems to be a genuinely new development: its so-called interpretative use (see Huddleston and Pullum 2002, p. 165) in such contexts as:

(1) I can only add that when Paul Gascoigne says he will not be happy until he stops playing football, he is talking rot. (F-LOB, A 09: 81f.)

(2) When he speaks of apocalypse, however, he is not speaking of it in the literal and popular sense. (Frown, D 02: 120f.)

\footnotetext{
${ }^{10}$ The phenomenon of the "stative progressive" tends to be curiously overrated in the literature on recent changes. In many cases apparent exceptional or innovative uses are the result of polysemy. Thus, forget in its sense of neglect (you're forgetting your mother) is clearly compatible with the progressive. In others, they can be easily handled as contextually licenced rule-breaking for communicative-rhetorical effect (as in are you seeing what I am seeing? - in which the point is that visual perception, which is normally subconscious, is made the subject of conscious reflection. See Visser (1973, p. 1973-1986) for a rich compilation of relevant data.
} 
In (1), the two predications 'says he will not be happy...' and 'is talking rot' must refer to precisely coterminous situations, since the second is merely a more abstract interpretation of the first. There is apparently no reason why one should be treated as imperfective against the background of the other. But what we seem to have here is a further extension of the basic uses of the progressive, namely seeing a situation 'from the inside' (Comrie 1976, p. 4), to the metacommunicative level. As Huddleston and Pullum put it, "the internal (imperfective) view is appropriate to the explanatory function of the clause - in emphasising duration, the progressive metaphorically slows down or extends the situation in order to be able to focus on clarifying its nature" (2002, p. 165). Example (2) is similar: here it is sufficient to note that the progressive (is ... speaking) and non-progressive (speaks) could by no means be interchanged. Another semantic extension of the progressive, to a 'future as a matter of course' interpretation (see Leech 1987, p. 68), appears to account for much of the increase observed between LOB and F-LOB in the modal progressive, especially with will (see Smith, 2003):

(3) He will be standing down at the next general election. (F-LOB, B 20:30)

(4) Why, you will be asking me to bomb Essen next. (F-LOB, F 24: 142)

Here the 'in-progress' meaning of the progressive applies, not to the action of 'standing down' or 'asking' itself, but to the circumstances already set in train and leading up to that action, which is assumed to take place in the not-too-distant future. One possible motive for using will + progressive , rather than the non-progressive will stand down, is that will $+\mathrm{V}$ can imply that the action will be actuated by the volition of the speaker or the subject referent. By using the progressive, the speaker disclaims or at least backgrounds that implication.

A more radical grammatical change is at stake in the second phenomenon mentioned above, the establishment of progressives in those few remaining niches of the verbal paradigm from 
which they were excluded up to the 20th century. With these constructions, the four corpora prove too small to yield conclusive results. The present perfect progressive passive is attested in none of them. The British data yield three instances of modalised passive progressives, two from LOB and one from F-LOB:

(5) To ridicule them only pushes them farther into themselves, so that they become unable to speak about it to anybody and the seeds of any amount of trouble are sown, the harvest of which may still be being reaped at forty or fifty. (LOB, D6: 16ff.)

(6) We have also to notice that while the entropy of our given system will increase with external or given time, this relation is not reciprocal, for, if we first choose our time, a rare state in our stationary process will just as likely be being approached as being departed from. (LOB, J18: 197ff.)

(7) So the news that a second park-and-ride route could be being introduced for a trial period at Clifton Moor north of the city should be welcomed, especially as Christmas is approaching. (F-LOB, B18: 109ff.)

The first thing to note about these examples is that the progressive is not obligatory yet in such constructions, a sign of their recentness. Secondly, the yield of examples from the four corpora, while clearly not conclusive in itself, is not fortuitous. Modal forms of the type represented by examples (5) to (7) are easy to find in the 100,000,000-word British National Corpus (with textual data from the late 20th century). The present perfect passive progressive, on the other hand, is attested just once:

(8) That er, er, little action has been taken in the last thirty forty years since this has been being discussed, erm, I think the first international conference erm, produced their own report in nineteen sixty. (BNC, JJG 542) 
Significantly, this example is from a transcription of spontaneous speech. Again, as in (5) to (7) above, the use of the progressive is not yet obligatory. Summarising the corpus data, we can say that the complex forms in question can be attested if the database is sufficient, and that their spread seems to take place more easily in the modal environments (be being) than in the present perfect (been being).

Another former lacuna in the use of the progressive was the progressive form of the copulaa use which can be traced back for about 200 years but probably was not fully established until late in the $19^{\text {th }}$ century (Jespersen, 1909-49, IV: 225f.). Here, the four corpora suggest that this construction (although still rare) has grown in frequency in written English between 1961 and 1991/2. There is an increase from 3 to 20 instances of the progressive copula from Brown to Frown, and from 8 to 17 from LOB to F-LOB.

\subsection{Modality: modal auxiliaries, so-called semi-modals, and the subjunctive}

It is well known that the class of modal auxiliaries emerged as a separate syntactic category around the beginning of the Early Modern English period, and that in the later modern period, there has been an ongoing grammaticalisation of some verbal constructions called "semimodals" such as have to and be going to, which in function and behaviour overlap with these modals. The semi-modals are a rather loosely-defined grouping of verbal idioms, which are much more frequent in spoken than in written English - indeed, some of them have acquired reduced pronunciations, reflected popularly in written forms such as gotta and gonna. In addition, the lexical verb want shows early signs of auxiliation/ grammaticalisation, including phonetic erosion in wanna (Krug 2000, p. 117-166); this is why, though not an established semi-modal yet, it is included in the list in Table 4 below. 
It has remained an open question how far the rise of these semi-modals has encroached on the use of modal auxiliaries. However, a study of the modals in our four corpora leaves no doubt that there is a decline in their use during the later 20th century, as shown in Table 3.

Table 3: Decline in the use of the modal auxiliaries in the four reference corpora

\begin{tabular}{|c|c|c|c|c|c|c|c|c|c|}
\hline & $\begin{array}{l}\text { British } \\
\text { LOB }\end{array}$ & $\begin{array}{l}\text { iglish } \\
\text { F-LOB }\end{array}$ & $\begin{array}{l}\text { Log* } \\
\text { likhd }\end{array}$ & Diff $(\%)^{* *}$ & & $\begin{array}{l}\text { Americ } \\
\text { Brown }\end{array}$ & $\begin{array}{l}\text { English } \\
\text { Frown }\end{array}$ & $\underline{\text { Log likhd }}$ & $\underline{\operatorname{Diff}(\%)}$ \\
\hline would & 3028 & 2694 & 20.4 & $-11.0 \%$ & would & 3053 & 2868 & 5.6 & $-6.1 \%$ \\
\hline will & 2798 & 2723 & 1.2 & $-2.7 \%$ & will & 2702 & 2402 & 17.3 & $-11.1 \%$ \\
\hline can & 1997 & 2041 & 0.4 & $+2.2 \%$ & can & 2193 & 2160 & 0.2 & $-1.5 \%$ \\
\hline could & 1740 & 1782 & 2.4 & $+2.4 \%$ & could & 1776 & 1655 & 4.1 & $-6.8 \%$ \\
\hline may & 1333 & 1101 & 22.8 & $-17.4 \%$ & may & 1298 & 878 & 81.1 & $-32.4 \%$ \\
\hline should & 1301 & 1147 & 10.1 & $-11.8 \%$ & should & 910 & 787 & 8.8 & $-13.5 \%$ \\
\hline must & 1147 & 814 & 57.7 & $-29.0 \%$ & must & 1018 & 668 & 72.8 & $-34.4 \%$ \\
\hline might & 777 & 660 & 9.9 & $-15.1 \%$ & might & 635 & 635 & 0.7 & $-4.5 \%$ \\
\hline shall & 355 & 200 & 44.3 & $-43.7 \%$ & shall & 267 & 150 & 33.1 & $-43.8 \%$ \\
\hline ought (to) & 104 & 58 & 13.4 & $-44.2 \%$ & ought (to) & 70 & 49 & 3.7 & $-30.0 \%$ \\
\hline need $+\mathrm{V}$ & 87 & 52 & 9.0 & $-40.2 \%$ & need & 40 & 35 & 0.3 & $-12.5 \%$ \\
\hline TOTAL & 14667 & 13272 & 73.6 & $-9.5 \%$ & TOTAL & 13962 & 12287 & 68.0 & $-12.2 \%$ \\
\hline
\end{tabular}

* Log likelihood is a measure of statistical significance: a value of 3.84 or more equates with chi-square values $>0.05$; a value of 6.63 or more equates with chi-square values $>0.01$.

** The column headed Diff (\%) gives the increase (+) or decrease (-) in occurrences as a percentage of the frequency in the 1961 corpora.

The counts include verb and negative contractions: i.e., under will are counted won't and 'll.

In this Table, the modals are listed in order of frequency in the LOB corpus, an ordering which varies comparatively little in the four corpora. There are, however, some big differences in the steepness of the fall in frequency. The least frequent modals - shall, ought to and need (in auxiliary construction) - have plummeted, and the mid-frequency modals must and may have also declined drastically. On the other hand, the most common modals will, can and would have maintained their position robustly. 
While BrE and AmE have been developing along broadly parallel lines (over-all loss of frequency by around $10 \%$ in both sets of corpora), it is nevertheless interesting to note that figures for AmE were already slightly lower in 1961, and the decline has been a little sharper in AmE since. This looks like a follow-my-leader situation, in which BrE is following in the track of AmE. Less clear trends are seen with the representatively varied set of semi-modals listed in Table 4. There is a rise in the over-all frequency of this class in BrE and AmE, but this is mainly due to the increases for need to, want to, and - in AmE - be going to. For other forms, there is stability, and in one case (be to) even a significant decline:

Table 4: Increase in the use of semi-modals in the four reference corpora

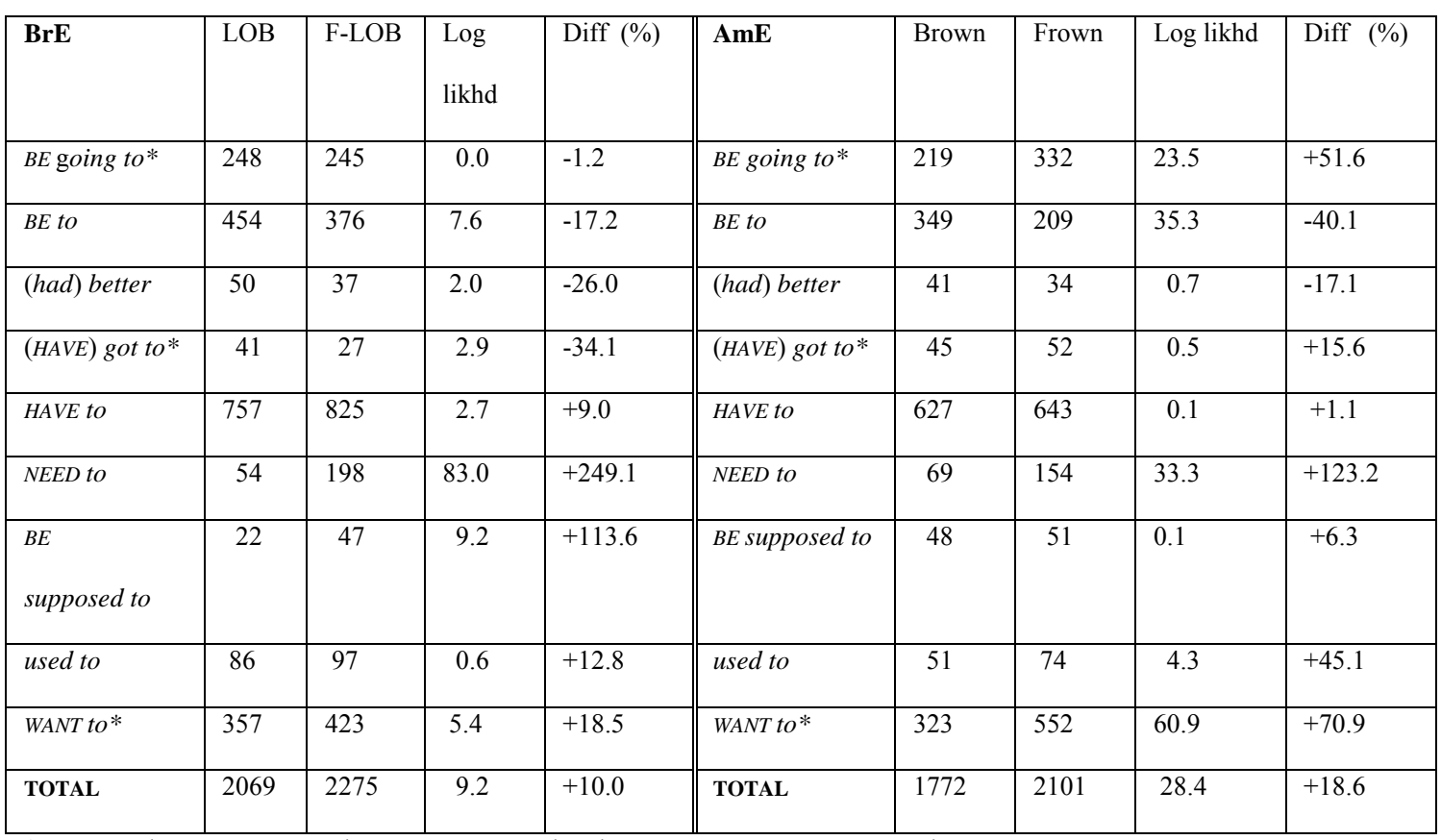

*Forms spelt gonna, gotta and wanna are counted under be going to, have got to, and want to.

Perhaps what is most striking is that the semi-modals in aggregate are so much less frequent than the modals: added together they are less frequent than the single modal will! From this evidence it is obviously difficult to mount a general argument that the semi-modals are increasing at the expense of the core modals. On the other hand, going beyond the evidence of Tables 3 and 4 to look at spoken data, there are two good reasons for seeing at least some link 
between the fall of the modals and the rise of the semi-modals. One reason is that the evidence from spoken corpora, ${ }^{11}$ covering much the same period, shows a steeper fall for the modals and rise for the semi-modals respectively. In the comparison between the two small spoken corpora, modals fall $-17.3 \%$ and semi-modals rise $+36.1 \%$, in contrast with the figures for LOB and F-LOB of $-9.5 \%$ and $+10.0 \%$ respectively. It has been impossible to make such a comparison for AmE, for which no such comparable corpora exist. However, a second striking result was arrived at by comparing overall frequency of modals and of semi-modals in a c. 4-million-word corpus of AmE conversation. ${ }^{12}$ Compared with a ratio of 1:5.9 (semimodals: modals) for both F-LOB and Frown, the AmE corpus of conversation yielded a ratio of 1:1.6. In other words, in current spontaneous dialogue among American speakers, semimodals are more than $60 \%$ as frequent as core modals (using the lists of modals and semimodals in Tables 3 and 4). This is vastly different from the picture we get from the written corpora of the $1990 \mathrm{~s}$, both American and British, where the comparable figure is only $17 \%$. It suggests that, as is often suspected, the spoken American variety of the language is the main driving-force of change in this area, as presumably in others, and places the encroachment of semi-modals on the territory of the modals in AmE speech, in frequency terms, beyond doubt. This has its most forthright demonstration in the fact that in the American conversational corpus mentioned above, HAVE (got) to is more than 10 times as frequent as must. ${ }^{13}$

\footnotetext{
${ }^{11}$ With the permission and help of Bas Aarts and Gerry Nelson at the Survey of English Usage (University College London) Leech was able to make a frequency analysis of (semi-)modals in two very small $(80,000$ words) but roughly comparable corpora of spoken BrE of approximately the early 1960s and the early 1990s. These are from corpora collected by the Survey: the SEU corpus and the ICE-GB corpus. Further details are given in Leech $(2003,2004)$.

${ }^{12}$ We are grateful to Della Summers, of Pearson Education, for permission to use this corpus, the Longman Corpus of Spoken American English. It was collected in the late 1990s on demographic principles, and consists largely of impromptu conversation.

${ }^{13}$ The argument presented here is generally compatible with the corpus-based findings in Biber et al., who also establish that semi-modals are more common in speech than writing and that two of them, namely have to and be going to, are particularly frequent in American English. However, they also point out that the trend is not unbroken and that have got to and had better are more usual in British English (1999, p. 487).
} 
In diametric contrast to the semi-modals, the subjunctive in English is a historical relic, more characteristic of formal written style than of the spoken language. Only two forms of it survive with any degree of currency, and even these are not morphologically distinctive, and can usually only be identified following singular subjects. These are the mandative subjunctive occurring in that-clauses following certain controlling items such as the verb suggest (10) and the so-called were-subjunctive signalling hypothetical meaning (11):

(10) Yesterday, he had suggested that he sleep in the spare room from now on. (F-LOB, K 22: 19f.)

(11) It felt as if she were alone in the world. (LOB, P 16: 79f.)

In the early-to-mid 20th century, it was imagined that the English subjunctive was reaching the end of its long road of decline. ${ }^{14}$ But for the later 20th century, the four corpora show a fascinating picture: whereas a gradual decline of the mandative subjunctive seems to continue in AmE, it has seen a modest revival, from a very low ebb, in British English - apparently under the influence of American English, where this form shows greater currency. ${ }^{15}$ The were-subjunctive, on the other hand, shows a continuing decline in $\mathrm{BrE}$ - from 95 occurrences to 41 in LOB and F-LOB.

\subsection{Nonfinite verbal forms}

Nonfinite verbal forms - infinitives, gerunds and participles - are another grammatical category which has become more functionally prominent, and correspondingly more frequent

\footnotetext{
${ }^{14}$ Serpollet (2001, p. 531) quotes this statement from Harsh (1968): "the inflected subjunctive, though hardly in a state of robust health, has been taking a long time to die. But that it is still dying [...] can hardly be denied".

${ }^{15}$ Serpollet (2001, p. 541) gives the following provisional frequency data for the mandative subjunctive from the four corpora: LOB $14 \rightarrow$ F-LOB 33 occurrences; Brown $91 \rightarrow$ Frown 78 occurrences. Hundt (1998, p. 163, 173), following a slightly different methodology, gets: LOB $12 \rightarrow$ F-LOB 44 . See further data on the British revival of the mandative subjunctive in Övergaard (1995).
} 
in discourse, since the Middle English period. In spite of the relative lack of attention that these forms have received in the literature on current change in English, there is no indication that the diachronic dynamic that characterised these forms in Early Modern English has abated in the recent past. Infinitival clauses with an explicit notional subject introduced by for (e.g. constructions such as it is easy for common ground to be forgotten in disputes over methods or they arranged for us to be met at the station) are clearly on the increase - from 294 instances in LOB to 332 in F-LOB ${ }^{16}$-, and so are gerundial complement clauses. For example, it is striking to see how recent the apparently rock-solid semantic contrast between infinitives and gerunds is after the verb remember. Since individual matrix verbs governing nonfinite complement clauses are usually not frequent enough to draw conclusions from the attestations in the four matching corpora, the data this time is provided by the quotation base of the OED ( $2^{\text {nd }}$ edition on CD-ROM), and the time frame is extended to three centuries - from 1700 to the present. Three constructional types are distinguished: (a) prospective to, as in the current I must remember to fill in the form, (b) retrospective-ing, as in I remember filling in the form, and (c) the now defunct retrospective construction with the infinitive, as in I remember to have filled in the form. Since the number of quotations available for the three centuries under review varies, frequencies are given as " $n$ occurrences/ 10,000 quotations":

Table 5: Gerunds and infinitives after remember in the OED quotation base - normalised frequencies ("n/ 10,000 quotes," rounded to the first decimal), with absolute frequencies in brackets

(a) prospective to

(b) retrospective -ing

(c) retrospective to

\footnotetext{
${ }^{16}$ This includes all uses of this functionally very versatile constructional pattern, which, in addition to the nounclause uses illustrated, also functions as postmodification in noun phrases (a tendency for job satisfaction to decrease with age) or as adverbial clause (for the plan to be successful, we need money and manpower), among others.
} 


\begin{tabular}{|l|r|r|r|}
\hline 18 th century & $5.5(15)$ & $1.8(5)$ & $4.8(13)$ \\
\hline 19 th century & $2.2(17)$ & $4.1(31)$ & $2.1(16)$ \\
\hline 20th century & $5.8(28)$ & $12.0(58)$ & $0.8(4)$ \\
\hline
\end{tabular}

The table reveals fluctuation - and structural stability - for prospective to, but a clear reversal of preferences for the retrospective uses, with the late $19^{\text {th }}$ century acting as the pivotal period of transition. Note in particular that the gerund increases to an extent greater than would have been necessary merely to compensate for the declining retrospective infinitive.

There is one matrix verb for which a growing popularity of the gerund is attested clearly even in the four matching corpora, namely begin. The increase seems to be restricted to American English so far.

Table 6: To-infinitives vs. V-ing after begin in the four reference corpora

\begin{tabular}{|l|l|l|}
\hline & 1961 & $1991 / 92$ \\
\hline British English (LOB: F-LOB) & $260: 23$ & $204: 20$ \\
\hline American English (Brown: Frown) & $230: 53$ & $202: 95$ \\
\hline
\end{tabular}

(BrE vs. AmE 1961 p $<0.001$; BrE vs. AmE 1991/92 p<0.001, BrE diachr. not significant, AmE diachr. $\mathrm{p}<0.001$ )

Close analysis of the data (Mair, 2002) reveals that, as expected, the diachronic development documented in the table is just one strand in a complex fabric of factors, including grammatical context, the partly contrasting semantic import of the gerundial and infinitival complement types, text-type specific preferences and the regional origin of a speaker/ writer. A final example, which is included chiefly because it shows British English diverging from US usage in the course of the $20^{\text {th }}$ century, is provided by prevent. Well into the recent past (c. 1900), this verb was variously used with or without the preposition from before the gerund in both British and American English (cf., e.g., the relevant entries in the OED or Websters $3^{\text {rd }}$ 
and Aarts 1992, p. 90-111 for a discussion of the theoretical aspects of this change). In the course of the $20^{\text {th }}$ century, however, the from-less variant was eliminated from American English, whereas it became increasingly common in British English, as is illustrated in Table 7:

Table 7: From vs. "zero" after prevent NP in the four reference corpora

\begin{tabular}{|l|l|l|}
\hline & 1961 & $1991 / 92$ \\
\hline British English (LOB: F-LOB) & $34: 7^{*}$ & $24: 24$ \\
\hline American English (Brown: Frown) & $47: 0$ & $36: 1^{* *}$ \\
\hline
\end{tabular}

(BrE diachr. $\mathrm{p}<0.01$; all other contrasts not significant)

* One of the seven instances of prevent NP V-ing in LOB has her as the notional subject of the gerund and could thus have been excluded as representing the "archaic" type (prevent my leaving) disregarded here.

** The sole American attestation of the "British" pattern (in Frown) is from a work of military history dealing with, significantly, the Battle of Britain.

\subsection{The colloquialisation of written English: passives and contractions}

Factors of genre, register and style are essential for the study of any grammatical change in progress as they promote or constrain the spread of an innovation throughout the language and the community. The phenomena dealt with in this section provide a particularly compelling illustration of this point, as they show that fairly dramatic changes can be documented in written corpora long after the actual forms under consideration have become established in the grammar.

The canonical be passive has been declining in frequency according to the evidence of the four written corpora, shown in Table 8:

Table 8: Decline in frequency of use of the be passive in the four reference corpora 


\begin{tabular}{|l|l|l|l|l|}
\hline & 1961 & $1991 / 92$ & Log lkhd & Diff (\%) \\
\hline British English (LOB/ F-LOB) & 13331 & 11708 & 109.8 & -12.4 \\
\hline American English (Brown/ Frown) & 11650 & 9329 & 263.7 & -20.1 \\
\hline
\end{tabular}

The picture this gives of the passive is remarkably similar to that given of the modals above, although the percentage loss of $12.4 \%$ for $\mathrm{BrE}$ and $20.1 \%$ for AmE is somewhat more dramatic. The passive is one of the foremost grammatical indicators of textual genre, and most common by far in academic writing (category $\mathrm{J}$ in the four corpora). Over the last two decades, prescriptive recommendations concerning its use have changed, with many style guides now advising against the use of passives in academic writing, especially in the United States. In a genre-differentiated analysis, Hundt and Mair accordingly noted a particularly pronounced decline in the frequency of passives in the Frown J-category, but were able to point out that the trend was significant in British English and in further textual genres (e.g. press), as well (1999, p. 231-2).

In theory, be-passives need not necessarily be replaced by active paraphrases, but could be being displaced by a rival construction, such as the get-passive. As Table 9 shows, this argument is impossible to defend. While the get passive has increased significantly, both in British and in American English, the increase is infinitesimal in terms of absolute figures and cannot compensate for the drop in be-passives:

Table 9: Rise in frequency of the use of get passives in the four reference corpora

\begin{tabular}{|l|l|l|}
\hline & 1961 & $1991 / 92$ \\
\hline British English (LOB/ F-LOB) & 34 & 53 \\
\hline American English (Brown/ Frown) & 35 & 64 \\
\hline
\end{tabular}

(significances: LOB-F-LOB $\mathrm{p}<0.05$, Brown: Frown $\mathrm{p}<0.01$; LOB-Brown and F-LOB-Frown $\mathrm{p}>0.05$ ) 
Certainly not the be passive, and not even the younger get passive, have been involved in any direct grammatical changes in the past century. Rather, the drop in be passives and the increase in get passives is a discourse phenomenon, pointing to the fact that in the course of the past century written English has moved closer to the norms of spoken usage. The be passive is comparatively rare in speech and is strongly associated with the written medium (particularly with academic writing - see, for example, Biber et al. 1999, p. 476). In the current social climate, demands for writing to be more accessible and readable affect writing practice in many fields - from journalism and academia to the design of official forms, and because of this a decrease in the frequency of the passive is to be expected. In those cases in which writers wish to use a passive, on the other hand, resistance to a traditionally spoken and informal form such as the get passive will be minimised.

Another striking case of written language progressively adopting norms of spoken language is the marked increase in the use of contracted forms evidenced in the four corpora. This applies both to verb contractions (as in it's, $\left.I^{\prime} l l\right)$ and to negative contractions (-n't) - see Table 10.

Table 10: Verb and negative contractions in the four corpora

\begin{tabular}{|l|l|l|l|l|l|}
\hline & & 1961 & $1991 / 92$ & Log Lkhd & Diff (\%) \\
\hline \multirow{2}{*}{ BrE (LOB/ } & verb contractions & 3143 & 3898 & 79.1 & $+23.7 \%$ \\
\cline { 2 - 6 } & negative contractions & 1950 & 2482 & 62.6 & $+26.9 \%$ \\
\hline \multirow{2}{*}{ AmE (Brown/ } & verb contractions & 2822 & 5073 & 644.6 & $+79.3 \%$ \\
\cline { 2 - 6 } & negative contractions & 2098 & 2983 & 152.5 & $+41.8 \%$ \\
\hline
\end{tabular}

The shift towards contracted forms is much more dramatic in AmE, but is also strong in BrE. As was the case with the passive, it could be argued that writers are not entirely free in their choice of form but influenced by prescriptive recommendations or, in the case of journalists, by even stricter conventions of house-style. But even a change in house-style in this case 
would just be a belated reflection of actual change in community preferences, and support the argument for a growing tendency towards the colloquialisation of written English.

\section{The changing noun phrase}

Preliminary analysis of some aspects of noun phrase structure in the four corpora has shown changes in frequency of use just as impressive as those we have reported for verb constructions. The most mysterious of these is an increase in BrE of over $5 \%$ for nouns ${ }^{17}$ (with a slightly lower figure of over $4 \%$ for AmE). So high is the frequency of nouns, particularly in prototypically written styles of English (e.g. news and academic prose - see Biber et al. 1999, p. 609-11) that this increase, though apparently small, is statistically highly significant (with a log likelihood of 350). Moreover, it seems to run contrary to the assumption - also defended in 4.4. above - that written English is being influenced by the spoken variety (where nouns are much less frequent). There is a corresponding increase in adjectives, together with a significant decrease in pronouns, articles and other determiners, which suggests that, instead of an increase in the number of noun phrases, the increase in nouns is due to a greater density of nouns and adjectives per noun phrase. Further analysis has shown, as part of the explanation for the reduction of article frequency, that the increase of nouns is partly due to an increase of proper nouns, especially the acronymic variety illustrated by IBM. Also, there has been a highly significant increase, in both $\mathrm{AmE}$ and $\mathrm{BrE}$, of noun + noun sequences (e.g. union leader, campaign coordinator, committee chairman):

Table 11: Noun + noun sequences: increasing frequency from LOB to F-LOB (frequency counts derived from unedited computer output)

\begin{tabular}{|l|l|l|l|l|}
\hline & LOB: frequency & F-LOB: frequency & Log likelihood & Difference (\%) \\
\hline
\end{tabular}

\footnotetext{
${ }^{17}$ For this and other changes in frequency of word classes between LOB and F-LOB, see Mair et al. (2002).
} 


\begin{tabular}{|l|r|r|r|r|}
\hline all noun + noun sequences & 32201 & 38016 & 466.3 & $+17.7 \%$ \\
\hline noun + common noun only & 20761 & 26539 & 691.9 & $+27.5 \%$ \\
\hline
\end{tabular}

The second row of the table indicates an even larger and more significant increase if the count excludes what the tagger regards as proper nouns in second position - in effect, excluding complex names such as Kansas City. This narrows down the nature of the change to commonnoun compounding expressions, suggesting a resurgence of the Germanic preference for noun + noun sequences over the more Romance-favoured prepositional phrase as a means of elaborating the content of noun phrases. This hypothesis is given some support from a decline (in LOB $\rightarrow$ F-LOB) of $2.9 \%$ for prepositions, and a greater decline of $4.7 \%$ for of-phrases in particular.

The above findings support recent work by Biber and Clark (2002), who have also noted that noun modification by clauses has been giving way to non-clausal modification strategies such as the use of premodifying nouns or post-modifying prepositional groups. Functionally, these structural trends suggest that noun phrases in written English are becoming somewhat denser and more compact in their presentation of information. This clearly goes against the tendency towards the informal and colloquial which was noted in many verb-phrase phenomena. Without going too far into detail, we would like to suggest one obvious way of resolving this apparent paradox. A comprehensive trend towards colloquialisation affecting all relevant grammatical markers of written style "across-the-board", as it were, is highly unlikely because it would represent a clearly dysfunctional development, making it difficult for the written language to fulfil one of its primary functions, which is the compression of information. A more compact, premodifying style of noun phrase elaboration is also promoted by the increasing use of another Germanic form, the s-genitive. The comparisons of LOB with FLOB and Brown with Frown show an increase of the s-genitive of $24.1 \%$ and $41.9 \%$ respectively, which certainly helps explain a decrease in the frequency of of-phrases. 
Inevitably, because the of-phrase is much more frequent and versatile than the s-genitive, the decline of of-phrases does not match the increase of s-genitives in percentage terms. But the competing relation between the two constructions shows up more sharply if the count is restricted to of-phrases which are semantically interchangeable with s-genitives. A provisional analysis of a small $2 \%$ sample of the four corpora on this basis showed a decline of s-genitivematched of-phrases of 23.4\% (BrE) and $24.2(\mathrm{AmE})$.

As for postmodification in the noun phrase, the most intriguing category to study from the point of view of recent change is the relative clause. Briefly, relativisation with wh-relative pronouns is giving way to relativisation using that or zero. As wh-relativisation is strongly associated with prototypical written registers (e.g. news and academic prose), this has to count as another instance of the colloquialisation of the written medium. A further parameterclosely connected with this - is the choice between the 'pied piping' construction with a preposed preposition (the project on which I'm working, etc.) and the preposition-stranding construction (the project I'm working on, etc.), where the preposition typically occurs in final position in the clause. Again, the tendency is to move away from preposing and toward stranding - perhaps another case where a more learned Romance overlay on English syntax is being undermined by a native Germanic construction more at home in the spoken language. ${ }^{18}$ Our frequency analysis of relativisation has so far had to rely on sample counts and (in the case of AmE) on tagging approximations with built-in correction factors (see note 9). In particular, the bracketed frequency figures in Table 12 lack the reliability of other tables. Nevertheless, it is unlikely that further confirmatory checks will change the general picture.

Table 12: Change in the use of relativisation devices

\begin{tabular}{|l|l|l|l|l||l|l|l|l|l|}
\hline BrE & LOB & F-LOB & Log likhd & Diff (\%) & AmE & Brown & Frown & Log likhd & Diff (\%) \\
\hline
\end{tabular}

\footnotetext{
${ }^{18}$ Altenberg (1982, p. 302), in a study of 17th century genitives and of-phrases, surmises that "the drift away from [the genitive] that had begun in late Old English seems to have reached its peak in the 17th century." If so, this trend appears to be now undergoing some reversal.
} 


\begin{tabular}{|l|l|l|l|l||l|l|l|l|l|}
\hline which & 4406 & 3997 & 21.0 & $-9.5 \%$ & which & 3516 & 2256 & 261.7 \\
\hline who & 2095 & 2013 & 1.9 & $-4.2 \%$ & who & 2164 & 2223 & 0.6 \\
\hline whom & 214 & 171 & 4.8 & $-20.1 \%$ & whom & 140 & 165 & $+2.4 \%$ \\
\hline whose & 293 & 244 & 4.6 & $-17.0 \%$ & whose & 246 & 255 & $+17.5 \%$ \\
\hline that * & $(1353)$ & $(1479)$ & $(5.2)$ & $(+9.0 \%)$ & that* & $(1829)$ & $(2710)$ & $(173.0)$ & $(+48.3 \%)$ \\
\hline zero** & $(253)$ & $(297)$ & $(3.4)$ & $(+17.1 \%)$ & zero** & $(191)$ & $(235)$ & $(4.6)$ \\
\hline pied-piping & 1401 & 1168 & 21.9 & $-16.9 \%$ & pied-piping & 1153 & 972 & $(+23.1 \%)$ \\
\hline preposition & $(18)$ & $(74)$ & $(36.4)$ & $(+310.0 \%)$ & preposition & $(91)$ & $(109)$ & $(1.6)$ \\
stranding* & & & & & stranding* & & $(+19.5 \%)$ \\
\hline
\end{tabular}

* The count of that-relatives is approximate: it depends on automatic tagging, and a margin of error is to be allowed for.

** These counts are based on sampling.

In $\mathrm{BrE}$, there has been a general decline in wh-relative pronouns, whereas in $\mathrm{AmE}$ it is the single pronoun which that has suffered extreme disfavour. This change is presumably due to a well-known interdict, in American style guides, against which as an introducer of restrictive relative clauses, and clearly that is the beneficiary of this ban. Since the texts in Frown were published (in 1992), the switch from which to that will no doubt have gone further, as a result of the widespread incorporation of the anti-which 'rule' in grammar checkers and word processors. $^{19}$

Before leaving the noun phrase, we should add a final word on pronouns, which provide one notable exception to the rule that syntactic change takes place below the threshold of conscious control. In 1961 the so-called 'generic' use of he for both male and female reference was well established, and hardly under threat. Conscious efforts inspired by the women's movement of the 1970s and 1980s, however, ensured that by 1991/2, generic he was declining fast, and various alternatives were jostling to fill the semantic gap left by its fall. Although the frequencies are low compared with third-person pronouns in general, the four corpora show the predictable changes. A sample of approximately 500 instances of he/him/his/himself from

\footnotetext{
${ }^{19}$ Such minor computer-driven changes in writing norms are, of course, merely the tip of an iceberg. The Internet/ World Wide Web and the various forms of computer-mediated communication associated with it have
} 
each corpus showed a decline of gender-neutral use from 32 (LOB) to 4 (F-LOB), and from 20 (Brown) to 7 (Frown). Oppositely, a comparable sample of they and its variants showed a rise in the use of singular they from 0 (LOB) to 9 (F-LOB), and from 7 (Brown) to 9 (Frown). Although rare in all four corpora, the gender-neutral coordinated pronouns he or she rose in frequency for the entire corpora from 11 to 37 (LOB $\rightarrow$ F-LOB) and from 9 to 56 (Brown $\rightarrow$ Frown). Ultimately, the need to plug the gap left by the demise of gender-neutral himself may lead to the establishment of a new pronoun themself-perhaps the clearest example of true grammatical innovation in standard English in our period. ${ }^{20}$

(11) You won't be the first or last man or woman who gets themself involved in a holiday romance. (BNC: K4D 386)

\section{Conclusion}

Although this survey of current change in English syntax has been necessarily selective, we have tried to achieve a reasonable coverage of core aspects of syntax by focusing on major categories in the verb phrase and noun phrase.

Before concluding it will be as well to consider very briefly what factors have been influencing the changes we have noted. One factor intrinsic to the functioning of any language at any time is grammaticalisation - which, as we saw in the cases of the progressive and the semi-modals, may take centuries to come to full fruition. A second factor is socio-cultural, and hence more specific to the social context of English in the $20^{\text {th }}$ century: colloquialisation, or the tendency for written language to adopt features associated with spoken language. There

already become a powerful force in language change on many levels - from lexical innovation to changes in discourse conventions.

${ }^{20}$ Themself is too rare in written English to appear in any of our four corpora. According to Huddleston and Pullum (2002, p. 494) it has been attested in standard English since the 1970s. The OED, which does not have an entry for themself, lists 41 mostly Middle English and Early Modern English occurrences in its quotation base, many of them with a distinctly nonstandard ring. 
are strong indications that such a process has been at work in the written language for centuries (see Biber and Finegan, 1989), and in this chapter we have noted such diverse cases as the increasing use of the progressive and semi-modals; the decline of wh-relative pronouns and the rise in the use of that and zero relative clauses; the growing use of contractions in written texts; the use of singular they. In written British English, a third factor Americanisation - intermingles with the other two. We have looked at one case - the apparent revival of the mandative subjunctive - where American influence seems to override colloquialisation, but often these two socio-cultural processes work together - for example, in the increasing use of semi-modals and the declining use of be passives. A fourth factor was touched on at the end of the last section - an ideological motivation (avoidance of sexual inequality) for replacing an older pronoun usage by a newer one. Such conscious movements for the change of language are rare, or at least are rarely successful. Hence there is something particularly unusual about this case, not least in the short time period that it took to produce a high-profile syntactic reform of language behaviour. Feminist recommendations in this case were clearly helped by the fact that singular they, which has a long history in the language, did not need to be promoted as a new form but was merely allowed to resurface in the standard after it had been proscribed by $18^{\text {th }}$ and $19^{\text {th }}$ century prescriptivists.

Although it may be fairly uncontroversial to say that such influences have been at work, it is virtually impossible to disentangle them, and to build a predictive model to account for kinds and degrees of frequency change taking place during a particular period. Processes such as colloquialisation and Americanisation are patchy and unpredictable in their results. One important linguistic factor to bear in mind is the competing relation between a spreading syntactic phenomenon and an alternative means of conveying the same meaning. In almost all the changes we have discussed, it is possible to name one (or more) competing construction(s): 


\begin{tabular}{lll} 
LOSING GROUND & \multicolumn{2}{l}{ GAINING GROUND } \\
$\begin{array}{lll}\text { modal auxiliary } & \text { v. } & \text { semi-modal } \\
\text { infinitive complement } & \text { v. } & \text { gerundial complement } \\
\text { be-passive } & \text { v. } & \text { get-passive } \\
\text { of-phrase } & \text { v. } & \text { s-genitive } \\
\text { wh-relative } & \text { v. } & \text { that or zero relativisation } \\
\text { gender-neutral he } & \text { v. } & \text { singular they or coordinated pronouns (he or she, } \\
& & \text { etc.) }\end{array}$
\end{tabular}

But the frequency picture rarely gives unequivocal support to the hypothesis that one form is being ousted or superseded by the other. The semantic and pragmatic parameters of linguistic choice are usually too complex to allow a simple inverse correlation to be observed of the

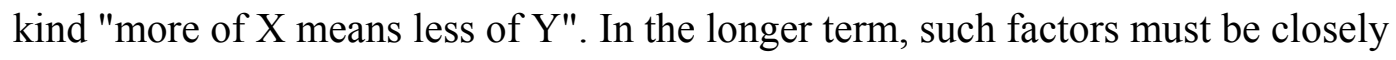
investigated if we are to develop more adequate models of syntactic change taking full account of changes in frequency or preference.

This chapter has demonstrated that there has been noticeable change in the past century even in a rigidly codified language variety such as written standard English, and that the spread of individual innovations can be documented in language corpora. Further, we have shown that those accounts of ongoing grammatical change that are based on anecdotal or impressionistic observation are generally unreliable. They can err in three ways: (1) suspecting change where there is stable long-term variability; (2) over-emphasising the importance of a small number of often marginal shibboleths important to prescriptivists; and (3) failing to notice the ever present groundswell of linguistic change, apparent in long-term developments in the core grammar. Further studies will have to account for the trends sketched here in the context of contemporary synchronic variation, in particular text-type variation and regional variation in standard Englishes world-wide. 


\section{References}

Aarts, B. (1992). Small clauses in English: the non-verbal types. Berlin: Mouton de Gruyter.

Aarts, F., \& B. Aarts (2002). Relative whom: 'a mischief-maker.' In A. Fischer, G. Tottie \& H.-M. Lehmann (Eds.). Text types and corpora. (pp. 123-130) Tübingen: Narr.

Altenberg, B. (1982). The genitive v. the of-construction: a study of syntactic variation in $17^{\text {th }}$ century English. Lund Studies in English 62. Lund: CWK Gleerup.

Barber, Ch. (1964). Linguistic change in present-day English. London and Edinburgh: Oliver \& Boyd.

Bauer, L. (1994). Watching English change: an introduction to the study of linguistic change in standard Englishes in the twentieth century. London: Longman.

Biber, D., \& Finegan, E. (1989). Drift and the evolution of English style: a history of three genres. Language, 65, 487-517.

Biber, D., Johansson, S., Leech, G., Conrad, S., \& Finegan, E. (1999). The Longman grammar of spoken and written English. London: Longman.

Biber, D., \& V. Clark (2002). Historical shifts in modification patterns with complex noun phrase structures. In T. Fanego et al. (Eds.). English historical syntax and morphology: selected papers from 11 ICEHL, Santiago de Compostela, 7-11 September 2000. (pp. 43-66) Amsterdam: JohnBenjamins.

Comrie, B. (1976). Aspect. Cambridge: CUP.

Denison, D. (1998). Syntax. In S. Romaine (Ed.). The Cambridge history of the English language, vol IV: 1776-1997. Cambridge: CUP. 92-329.

Harsh, W. (1968.) The subjunctive in English. Tuscaloosa, AL: University of Alabama Press.

Hopper, P., \& Traugott, E. (2003). Grammaticalization. $2^{\text {nd }}$ ed. Cambridge: CUP.

Huddleston, R., \& Pullum, G. K. (2002). The Cambridge grammar of the English language. Cambridge: CUP. 
Hundt, M. (1998). It is important that this study (should) be based on the analysis of parallel corpora: on the use of the mandative subjunctive in four major varieties of English. In H. Lindquist et al. (Eds). The major varieties of English: papers from MAVEN 97, Växjö 20-22 November 1997. (pp. 159-173). Växjö: Växjö University Press.

Hundt, M. (2001). What corpora tell us about the grammaticalisation of voice in getconstructions. Studies in Language, 25, 49-87.

Hundt, M., \& Ch. Mair (1999). 'Agile' and 'uptight' genres: the corpus-based approach to language-change in progress. International Journal of Corpus Linguistics, 4, 221-242.

Jespersen, O. (1909-49). A modern English grammar on historical principles. 7 vols. Copenhagen: Munksgaard.

Leech, G. (1987). Meaning and the English verb. (2nd ed.) London: Longman. (3rd ed. forthcoming 2004.)

Leech, G. (2003). Modality on the move: the English modal auxiliaries 1961-1992. In R. Facchinetti, M. Krug \& F. Palmer (Eds). Modality in contemporary English. (pp. 223240). Berlin/New York: Mouton de Gruyter.

Leech, G. (2004). Recent grammatical change in English: data, description, theory. In B. Altenberg \& K. Aijmer (Eds). Advanced in corpus linguistics: proceedings of the $23^{\text {rd }}$ ICAME Conference, Gothenburg, 2002. (pp. 61-81). Amsterdam: Rodopi.

Lightfoot, D. (1979). Principles of diachronic syntax. Cambridge: CUP.

Lightfoot, D. (1999). The development of language: acquisition, change, and evolution. Malden, MA: Blackwell.

Mair, Ch., \& Hundt, M. (1995). Why is the progressive becoming more frequent in English? A corpus-based investigation of language change in progress. Zeitschrift für Anglistik und Amerikanistik, 43, 111-122.

Mair, Ch. (1997). The spread of the going-to-future in written English: a corpus-based investigation into language change in progress. In R. Hickey \& St. Puppel (Eds). 
Language history and linguistic modelling: a festschrift for Jacek Fisiak on his $60^{\text {th }}$ birthday. (pp. 1537-1543). Berlin: Mouton de Gruyter.

Mair, Ch. (2002). Three changing patterns of verb complementation in Late Modern English: a real-time study based on matching text corpora. English Language and Linguistics, $6,105-131$.

Mair, Ch., Hundt, M., Leech, G., \& Smith, N. (2002). Short term diachronic shifts in part-ofspeech frequencies: a comparison of the tagged LOB and F-LOB corpora. International Journal of Corpus Linguistics, 7, 245-264.

Nehls, D. (1988). On the development of the grammatical category of verbal aspect in English. In J. Klegraf \& D. Nehls (Eds). Essays on the English language and applied linguistics on the occasion of Gerhard Nickel's 60th birthday. (pp. 173-198). Heidelberg: Groos.

Nevalainen, T., \& H. Raumolin-Brunberg. (2003). Historical sociolinguistics: language change in Tudor and Stuart England. London: Longman.

Olofsson, A. (1990). A participle caught in the act: on the prepositional use of following. Studia Neophilologica, 62, 23-35, 129-149.

Övergaard, G. (1995). The mandative subjunctive in American and British English in the 20th century. Stockholm: Almqvist \& Wiksell International.

Rickford, J., Mendoza-Denton, N., Wasow, T., \& Espinosa, J. (1995). Syntactic variation and change in progress: loss of the verbal coda in topic restricting as far as constructions." Language, 71, 102-31.

Romaine, S., \& Lange, D. (1991). The use of like as a marker of reported speech and thought: a case of grammaticalization in progress. American Speech, 66, 227-279.

Sapir, E. (1921). Language: an introduction to the study of speech. New York: Harcourt, Brace \& Co. 
Serpollet, N. (2001). The mandative subjunctive in British English seems to be alive and kicking ... Is this due to the influence of American English? In P. Rayson, A. Wilson, T. McEnery, A. Hardie \& S. Khoja (Eds). Proceedings of the Corpus Linguistics 2001 Conference. Lancaster University: UCREL Technical Papers Vol. 13, 531-542.

Smith, N. (2002). Ever moving on? The progressive in recent British English. In P. Peters, P. Collins \& A. Smith (Eds). New frontiers of corpus research: papers from the twenty first International Conference on English Language Research on Computerized Corpora, Sydney 2000. (pp.317-330). Amsterdam: Rodopi.

Smith, N. (2003a). A quirky progressive? A corpus-based exploration of the will + be + -ing construction in recent and present day British English. In D. Archer, P. Rayson, A. Wilson \& T. McEnery (Eds). Proceedings of the Corpus Linguistics 2003 Conference. Lancaster University: UCREL Technical Papers Vol. 16, 714-723.

Smith, N. (2003b). Changes in the modals and semi-modals of strong obligation and epistemic necessity in recent British English. In R. Facchinetti, M. Krug \& F. Palmer (Eds). Modality in contemporary English. (pp. 241-266). Berlin/New York: Mouton de Gruyter.

Visser, F. Th. (1973). An historical syntax of the English language. Vol. 3, part 2. Leiden: Brill.

\section{Further reading}

Aitchison, J. (1991). Language change: progress or decay. $2^{\text {nd }}$ ed. Cambridge: CUP.

Bauer, L. (1994). Watching English change: an Introduction to the study of linguistic change in standard Englishes in the twentieth century. London: Longman.

Barber, Ch. (1964). Linguistic change in present-day English. London and Edinburgh: Oliver \& Boyd. 
Bybee, J., \& Hopper, P. (Eds). (2001). Frequency and the emergence of linguistic structure. Amsterdam: Benjamins.

Croft, W. (2000). Explaining language change: an evolutionary approach. London: Longman.

Crystal, D. (2001). Language and the internet. Cambridge: CUP.

Denison, D. (1998). Syntax. In S. Romaine (Ed.). The Cambridge history of the English language, vol IV: 1776-1997. Cambridge: CUP. 92-329.

Krug, M. (2000). Emerging English modals: a corpus-based study of grammaticalization. Berlin/ New York: Mouton de Gruyter.

Leech, G. (2003). Modality on the move: the English modal auxiliaries 1961-1992. In R. Facchinetti, M. Krug \& F. Palmer (Eds). Modality in contemporary English. (pp. 223240). Berlin/New York: Mouton de Gruyter.

Potter, S. (1975). Changing English. 2nd ed. London: Deutsch.

CHRISTIAN MAIR was Assistant and, subsequently, Associate Professor in the English Department of the University of Innsbruck, Austria, before being appointed to a Chair in English Linguistics at the University of Freiburg in Germany in 1990. He has been involved in the compilation of several corpora (among them F-LOB and Frown and - currently in progress - a corpus of Caribbean English as part of the International Corpus of English and an extension to the ARCHER corpus). His research over the past two decades has focussed on the corpus-based description of modern English grammar and regional variation and ongoing change in standard Englishes world-wide and resulted in the publication of one monograph (Infinitival clauses in English: a study of syntax in discourse, 1990) and more than 40 contributions to scholarly journals and edited works. 
GEOFFREY LEECH is Emeritus Professor of English Linguistics at Lancaster University, England, having taught in the same university since 1969. His publications include (with Randolph Quirk, Sidney Greenbaum and Jan Svartvik) A comprehensive grammar of the English language (1985), (with Jan Svartvik) A communicative grammar of English (1975; $3^{\text {rd }}$ edn 2002), Meaning and the English Verb (1971; $2^{\text {nd }}$ edn 1987), and (with Garside and Sampson) The computational analysis of English (1987). Since the 1970s, much of his research has been in corpus linguistics, and he has played a major role in the compilation, annotation and use of the LOB Corpus and the British National Corpus. 